\title{
Functionalized Carbon Nanotubes for Chemical Sensing: Electrochemical Detection of Hydrogen Isotopes
}

\author{
Stefan-Marian Iordache $1,2\left(\mathbb{D}\right.$, Eusebiu Ilarian Ionete ${ }^{3, *} \mathbb{0}$, Ana-Maria Iordache ${ }^{1,2, *}$, Ioan Stamatin ${ }^{2, *}$, \\ Nicolae Catalin Zoita ${ }^{1}\left(\mathbb{D}\right.$, Arcadie Sobetkii ${ }^{4, *}$ and Cristiana Eugenia Ana Grigorescu ${ }^{1, *}$ (D)
}

1 Optospintronics Department, National Institute for Research and Development in Optoelectronics-INOE 2000, 409 Atomistilor, 077125 Magurele, Romania; stefan.iordache@inoe.ro (S.-M.I.); cnzoita@inoe.ro (N.C.Z.)

2 3Nano-SAE Research Center, Faculty of Physics, University of Bucharest, 405 Atomistilor, P.O. Box MG-38, 077125 Magurele, Romania

3 National R\&D Institute for Cryogenics and Isotopic Technologies-ICSI Rm.Valcea, 4 Uzinei Str. RM Valcea, 240050 Valcea, Romania

4 MGM Star Construct, 7B Pancota Str., 022773 Bucharest, Romania

* Correspondence: eusebiu.ionete@icsi.ro (E.I.I.); ana.iordache@inoe.ro (A.-M.I.); istarom@3nanosae.org (I.S.); sobetkii@yahoo.com (A.S.); cgrigor@inoe.ro (C.E.A.G.); Tel.: +40-314-05-07-91 (C.E.A.G.)

Citation: Iordache, S.-M.; Ionete, E.I.; Iordache, A.-M.; Stamatin, I.; Zoita,

N.C.; Sobetkii, A.; Grigorescu, C.E.A.

Functionalized Carbon Nanotubes for Chemical Sensing: Electrochemical Detection of Hydrogen Isotopes. Coatings 2021, 11, 968. https:// doi.org/10.3390/coatings11080968

Academic Editor: Dimitrios Tasis

Received: 5 July 2021

Accepted: 11 August 2021

Published: 14 August 2021

Publisher's Note: MDPI stays neutral with regard to jurisdictional claims in published maps and institutional affiliations.

Copyright: (C) 2021 by the authors. Licensee MDPI, Basel, Switzerland. This article is an open access article distributed under the terms and conditions of the Creative Commons Attribution (CC BY) license (https:/ / creativecommons.org/licenses/by/ $4.0 /)$.

\begin{abstract}
In this study, we propose a palladium-functionalized CNT composite working as a sensitive material to evaluate the deuterium concentration in aqueous samples. The sensitive material was prepared by the deposition of Pd nanoparticles onto MWCNT-OH by the micellization process. A modified electrode was prepared by drop casting $60 \mu \mathrm{L}$ of Pd-decorated MWCNT suspension on a clean glassy carbon electrode surface. The sensing behavior was investigated in a series of deuterium-enriched solutions ranging from 25 to 10,000 ppm. We performed cyclic voltammetry and impedance spectroscopy studies on the samples. The process is quasi-reversible with the reduction curve more pronounced than the oxidation curve, which indicates a low tendency to desorption for the hydrogen atoms.
\end{abstract}

Keywords: CNT functionalization; coating by dropcast; hydrogen isotope detection; palladium; cyclic voltammetry; impedance spectroscopy

\section{Introduction}

There is an intense demand for heavy water production and tritium decontamination in the nuclear industry. Heavy water is used as the moderator for many nuclear reactors and is responsible for the removal of tritium isotopes produced by them [1] to ensure optimal performance during their operation. Moreover, large amounts of tritium are required by experimental fusion laboratories that use this isotope as a fuel. Cryogenic distillation is the most used method for isotope separation, but it is expensive because: (i) the natural abundance of deuterium is very low, which in turn implies processing thousands of tons of water to obtain the desired enrichment, and (ii) the distillation process has many stages in order to achieve the degree of separation. The ability of palladium to absorb hydrogen is well known [2,3]. Together with Pt-based alloys [4] and multinary metal alloys [5], platinum-based alloys have been researched as alternatives for fuel cells and hydrogen storage applications. Pd exhibits high catalytic activity, particularly for hydrogen evolution reactions, and plays an important role in many electrochemical processes (not only as a catalyst but also as an inhibitor in oxygen evolution reactions) [6,7]. Although there are some interesting studies about the versatility of electrochemical sensors in assessing heavy metal trace detection [8], information about the behavior of palladium in heavy water is scarce [9]. This is the main reason why we propose an electrochemical device to evaluate the deuterium concentration in aqueous samples. The sensitive material is based on palladiumfunctionalized carbon nanotubes (CNTs), a composite material that shows high affinity 
towards the identification of hydrogen isotopes. Based on previous research [10], we employed the same composite material (Pd-decorated MWCNT), developed via the reverse micelle synthesis route [11], to fabricate an electrochemical sensor, which can monitor the level of deuterium in heavy water. In this study, we focused on the electrochemical performance of the composite as the main characterization method. The results obtained during cyclic voltammetry and impedance spectroscopy are discussed in this paper. Other techniques used to characterize the composite are presented in our previous work [10] and are not re-discussed here.

\section{Materials and Methods}

\subsection{Materials}

Reagents: $\mathrm{PdCl}_{2}$ (Sigma Aldrich, Burlington, MA, USA), cyclohexane, iso-propanol, hydrazine (Merck, Darmstadt, Germany) —all are of analytical grade and were used without further purification. Solvent-ultrapure water from Millipore, with resistance $\geq 18 \mathrm{M} \Omega$. Surfactant-Tween20 (Polyoxyethylene (20) sorbitan monolaurate) (Sigma Aldrich, Burlington, MA, USA) which is a nonionic surfactant with $\mathrm{CMC}=8.04 \times 10^{-5} \mathrm{M}, \mathrm{MW}=1227.54 \mathrm{~g} / \mathrm{mol}$ and $\mathrm{d} \sim 1.1 \mathrm{~g} / \mathrm{cm}^{3}$ ) [12,13]. Carbon nanotubes-MWCNT-OH, hydroxylated multi-wall carbon nanotubes (Shenzhen Nanotech Port Co. Ltd., Shenzhen, China), with catalogue data: diameter $2-10 \mathrm{~nm}$, length $5-15 \mu \mathrm{m}$, carbon content $>97 \%$, ash content $2 \%$, hydroxyl ratio $\sim 2.97 \%\left({ }^{-} \mathrm{OH} / \mathrm{C}\right)$, carbon hydroxylated on CNTs $\sim 6-8 \%\left(\mathrm{C}^{-} / \mathrm{C}\right)$.

\section{Deposition of Pd Nanoparticles onto MWCNT-OH Substrate}

Pd nanoparticles were deposited on MWCNT-OH by micellization process. The synthesis method has been described in detail in the Supplementary File of [10]. Briefly, micelle preparation was performed as follows: in a mixture of four solvents $(2.2 \mathrm{M}$ cyclohexane, $5.5 \mathrm{M}$ iso-propanol and $8.14 \times 10^{-5} \mathrm{M}$ Tween 20 in distilled water; the concentration of Tween was chosen slightly above CMC to ensure the formation of colloids), ultrasonicated for $30 \mathrm{~s}$ in an ultrasonic processor (UIP1000hd, $20 \mathrm{kHz}, 100 \mathrm{~W}$, Hielscher Ultrasonics GmbH, Teltow, Germany), $30 \mathrm{mg}$ (corresponding to $3.4 \times 10^{-3} \mathrm{M}$ ) $\mathrm{PdCl}_{2}$ and $0.1 \mathrm{mg} \mathrm{MWCNT}-\mathrm{OH}$ were added with continuous ultrasonication for $60 \mathrm{~s}$ to ensure complete dissolution of $\mathrm{PdCl}_{2}[14] . \mathrm{Pd}^{2+}$ ions were reduced with hydrazine $(0.63 \mathrm{M})$ under mild stirring at room temperature. After $24 \mathrm{~h}$, the precipitate was filtered, repeatedly washed with distilled water and dried at $120^{\circ} \mathrm{C}$. The Pd/MWCNT composite was stored under inert atmosphere until use for the sensor fabrication.

\subsection{Electrochemical Characterization}

\subsubsection{Preparation of the Modified Electrode}

A total of $1.7 \mathrm{mg} \mathrm{Pd} / \mathrm{MWCNT}$ was dispersed in $1.5 \mathrm{~mL}$ ultrapure water and sonicated for half an hour to obtain a stable suspension. Before electrode modification, the glassy carbon electrode (GCE) (Metrohm AG, Herisau, Switzerland) was polished with alumina powder and sonicated in water until the surface was completely clean and had a mirror appearance. Then, $60 \mu \mathrm{L}$ of the Pd/MWCNT suspension was dropcasted onto the clean surface of the GCE and allowed to dry $\left(\mathrm{D}_{\mathrm{GCE}}=0.8 \mathrm{~cm}\right.$ and the geometric area, $\left.\mathrm{A}_{\mathrm{GCE}}=0.5024 \mathrm{~cm}^{2}\right)$.

\subsubsection{Experimental Set-up for the Electrochemical Characterization}

The electrochemical analysis was performed with a Voltalab 40 system (Radiometer Analytical, Villeurbanne, France) in a typical three-electrode cell: (1) a working electrode of glassy carbon, modified with Pd/MWCNT; (2) $\mathrm{Ag} / \mathrm{AgCl} 3 \mathrm{M} \mathrm{KCl}$ as reference electrode; (3) a platinum wire as auxiliary electrode. Four concentrations of deuterated water were investigated: $1120 \mathrm{ppm}( \pm 200 \mathrm{ppm}), 2100 \mathrm{ppm}( \pm 200 \mathrm{ppm}), 5030 \mathrm{ppm}( \pm 300 \mathrm{ppm})$ and $9880 \mathrm{ppm}( \pm 300 \mathrm{ppm})$. The blank electrolyte was a type of purified water, with scarce ${ }^{2} \mathrm{H}$ isotope content (Qlarivia ${ }^{\circledR}$, Ramnicu Valcea, Romania, with $25 \mathrm{ppm} \pm 5 \mathrm{ppm}{ }^{2} \mathrm{H}$ ), mineralized with $\mathrm{Ca}^{2+}, \mathrm{Mg}^{2+}$ and $\mathrm{Na}^{+}$salts. The characteristics of the samples are summarized 
in Table 1. For each sample, cyclic voltammetry (CV) and dynamic impedance (EIS) measurements were performed. Cyclic voltammetry was performed between -0.5 and $0.6 \mathrm{~V}$, with scan rates varying from 50 to $500 \mathrm{mV} / \mathrm{s}$, and the EIS measurements were collected between 1 and $10^{5} \mathrm{~Hz}$ and a modulation amplitude of $5 \mathrm{mV}$ in the same electrochemical assembly as for cyclic voltammetry. The spectra were collected using VoltaMaster4 software (Radiometer Analytical, Villeurbanne, France). All Pd/MWCNT-modified GCEs were activated before testing by running 20 cycles of $\mathrm{CV}$ at $100 \mathrm{mV} / \mathrm{s}$.

Table 1. Main characteristics of the investigated samples.

\begin{tabular}{|c|c|c|c|c|c|c|c|}
\hline Sample & $\begin{array}{l}\text { Working } \\
\text { Electrode }\end{array}$ & $\begin{array}{c}{ }^{2} \mathrm{H} \text { Concentration } \\
(\mathrm{ppm})\end{array}$ & $p H$ & $\left|E_{p c}\right|(\mathrm{mV})$ & $\left|E_{p a}\right|(\mathrm{mV})$ & $I_{p c}\left(\mu \mathrm{A} / \mathrm{cm}^{2}\right)$ & $I_{p a}\left(\mu \mathrm{A} / \mathrm{cm}^{2}\right)$ \\
\hline S1 & $\mathrm{Pd} / \mathrm{MWCNT} / \mathrm{GCE}$ & 1120 & 8.24 & 31.6 & 227.5 & 75.648 & 15.046 \\
\hline $\mathrm{S} 2$ & $\mathrm{Pd} / \mathrm{MWCNT} / \mathrm{GCE}$ & 2100 & 7.80 & 59 & 234 & 101.226 & 29.4 \\
\hline S3 & $\mathrm{Pd} / \mathrm{MWCNT} / \mathrm{GCE}$ & 5030 & 7.62 & 83.1 & 215 & 128.344 & 35.178 \\
\hline S4 & $\mathrm{Pd} / \mathrm{MWCNT} / \mathrm{GCE}$ & 9880 & 7.47 & 103 & 185 & 154.9 & 41.477 \\
\hline Blank & $\mathrm{Pd} / \mathrm{MWCNT} / \mathrm{GCE}$ & 25 (Qlarivia ${ }^{\circledR}$ ) & 7.66 & 144 & 403 & 108.317 & 28.781 \\
\hline GCE & GCE & 25 (Qlarivia $^{\circledR}$ ) & - & - & - & - & - \\
\hline
\end{tabular}

Abbreviations: ${ }^{2} \mathrm{H}=$ deuterium isotope; $\mathrm{E}_{\mathrm{pc}}=$ potential for the cathodic peak; $\mathrm{E}_{\mathrm{pa}}=$ potential for the anodic peak; $\mathrm{I}_{\mathrm{pc}}=$ current for the cathodic peak; $\mathrm{I}_{\mathrm{pa}}=$ current for the anodic peak.

\subsection{Characterization Methods}

Structural and morphological analyses on the Pd/MWCNT composite were presented in detail in [10] and are not discussed here. However, it is worth mentioning that those were performed by SEM, TEM, EDX and Raman spectroscopy.

\section{Results and Discussion}

\subsection{Pd/MWCNT Morphology}

The morphology and structure of the Pd/MWCNT composite [10] investigated by the above-mentioned techniques indicated a non-homogenous distribution of Pd nanoparticles onto the MWCNTs. The sizes of the metallic particles were below $10 \mathrm{~nm}$ (usually between 5.1 and $8 \mathrm{~nm}$ ) and the size of the MWCNTs was in the range 10.5-24.8 nm. The Pd nanoparticles appeared to be clustered onto specific regions of the nanotube in a comparable gravimetric ratio between $\mathrm{Pd}$ and $\mathrm{C}$. This means that the Pd nanoparticles were interlocked between the carbon nanotubes and anchored onto the previously hydroxylated sites on the carbon nanotubes, which is not uncommon.

\subsection{Electrochemical Characterization of Pd/MWCNT in Deuterated Water}

The electrochemical behavior of the Pd/MWCNT composite towards ${ }^{2} \mathrm{H}$ was investigated. Four samples with different concentrations of deuterium isotope were prepared. A commercially available type of water, Qlarivia ${ }^{\circledR}$, with a low concentration of ${ }^{2} \mathrm{H}$ (but mineralized, to work as an electrolyte) was used as a blank sample. Its content of deuterium is $25 \mathrm{ppm}( \pm 5 \mathrm{ppm})$. The salts used for mineralization in Qlarivia ${ }^{\circledR}$ are: $\mathrm{Ca}^{2+}\left(\mathrm{E}^{0} \mathrm{Ca}^{2+} / \mathrm{Ca}^{0}=-2.84 \mathrm{~V}\right), \mathrm{Mg}^{2+}\left(\mathrm{E}^{0} \mathrm{Mg}^{2+} / \mathrm{Mg}^{0}=-2.356 \mathrm{~V}\right), \mathrm{Na}^{+}\left(\mathrm{E}^{0} \mathrm{Na}^{+} / \mathrm{Na}^{0}=-2.714 \mathrm{~V}\right)$, $\mathrm{NO}_{3}{ }^{-}\left(\mathrm{E}^{0}\right.$ has three oxidation potentials, at $0.957 \mathrm{~V}, 0.94 \mathrm{~V}$ and $0.8 \mathrm{~V}$, dependent on the reaction products), $\mathrm{Cl}^{-}\left(\mathrm{E}^{0} \mathrm{Cl}^{-} / \mathrm{Cl}^{0}=-1.358 \mathrm{~V}\right)$ and $\mathrm{SO}_{4}{ }^{2-}\left(\mathrm{E}^{0}=0.158 \mathrm{~V}\right)$ [15].

The different types of samples are presented in Table 1 , together with the characteristics of the electrochemical response, resulting from cyclic voltammetry.

Figure 1 presents the cyclic voltammetry of the four samples of deuterated water (S1-S4) on the Pd/MWCNT composite, at a scan rate of $50 \mathrm{mV} / \mathrm{s}$. The bare GCE has no electrochemical response, which shows that the solutions are only active in the presence of the sensitive composite Pd/MWCNT. Additionally, the chosen potential interval is "blind" to other interfering reactions. For the modified electrode, Pd/MWCNT deposited onto GCE (Pd/MWCNT/GCE), two peaks are observed: a reduction peak $(\approx 50-80 \mathrm{mV})$ and an oxidation plateau, at $\approx 200 \mathrm{mV}$, which indicates that the reaction is somewhat reversible. 
The composite has an enhanced reactivity towards hydrogen, shown in the CVs as the reduction peak. This cathodic current corresponds to the absorption of ${ }^{2} \mathrm{H}$ by the $\mathrm{Pd}$ nanoparticles. Since the cathodic peak is more pronounced than the oxidation peak, we can assume that the ${ }^{2} \mathrm{H}$ is bound as Pd hydride and has a low tendency to desorb. The reaction associated with the absorption of ${ }^{2} \mathrm{H}$ inside the crystal lattice of $\mathrm{Pd}$ is presented in Equation (1):

$$
\mathrm{Pd}+{ }^{2} \mathrm{H}^{+}+e^{-} \leftrightarrows\left(\mathrm{Pd}-{ }^{2} \mathrm{H}\right)_{n}
$$

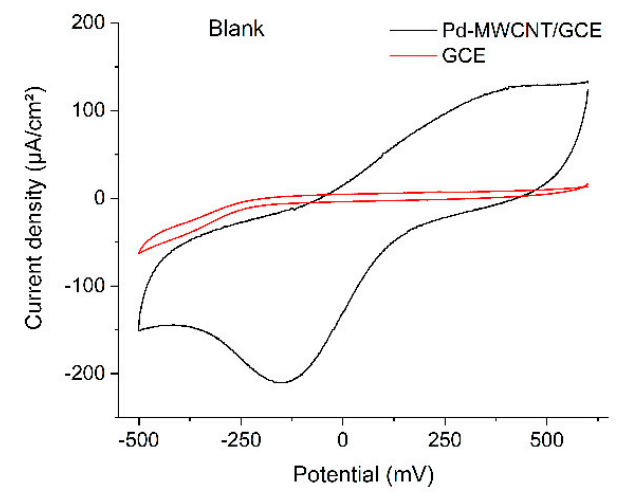

(a)

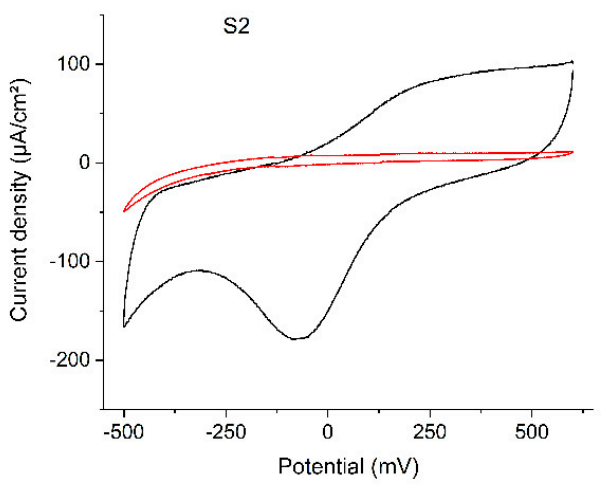

(c)

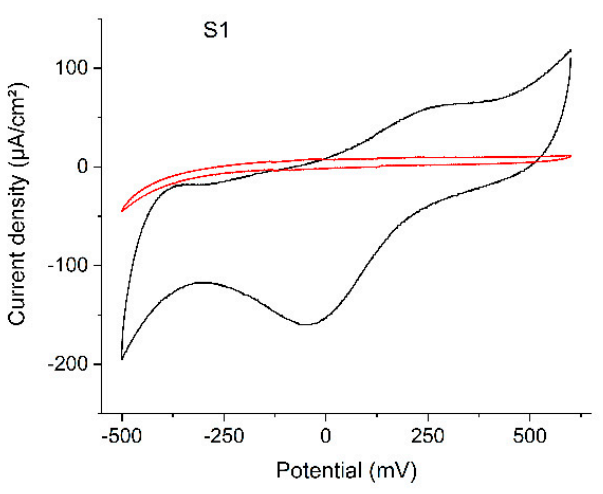

(b)

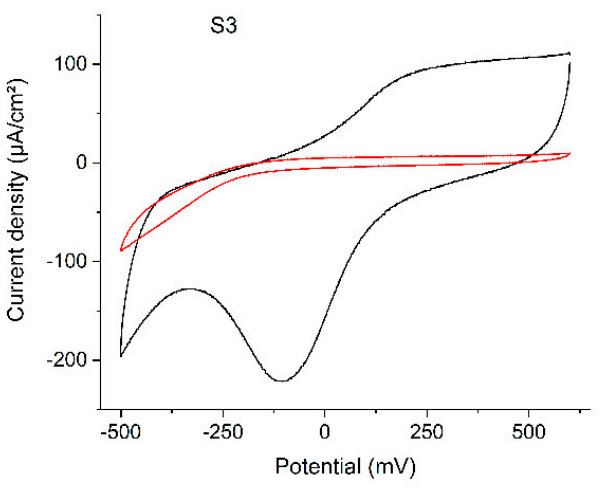

(d)

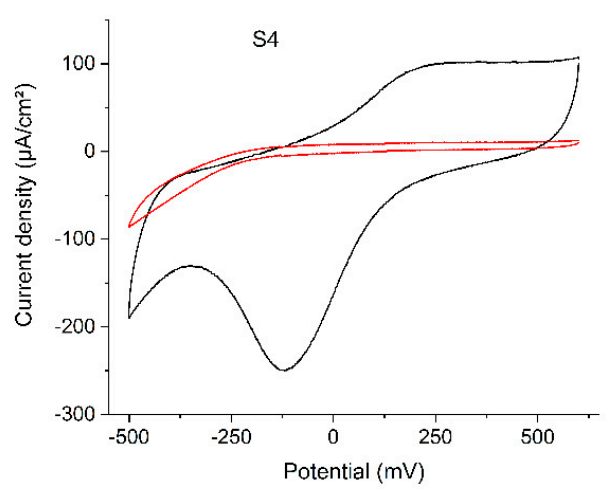

(e)

Figure 1. Cyclic voltammetry of the unmodified GCE (red line) and the Pd/MWCNT/GCE (black line) in the deuterated aqueous solutions (a) 25 ppm, (b) 1120 ppm, (c) 2100 ppm, (d) 5030 ppm and (e) 9880 ppm, at a scan rate of $50 \mathrm{mV} / \mathrm{s}$, vs. the $\mathrm{Ag} / \mathrm{AgCl} 3 \mathrm{M} \mathrm{KCl}$. 
The reversible potential for the $\mathrm{Pd}-{ }^{2} \mathrm{H}$ system is at $+29 \mathrm{mV}$ (vs. $\mathrm{Pt} /{ }^{2} \mathrm{H}$ reference electrode), according to Schuldiner and Hoare [16]. Since our working electrode consists of Pd nanoparticles deposited onto MWCNT, which are dropcasted onto the GCE, and the reference electrode is $\mathrm{Ag} / \mathrm{AgCl} 3 \mathrm{M} \mathrm{KCl}$, the potential of $-31.6 \mathrm{mV}$, observed for the $1120 \mathrm{ppm}{ }^{2} \mathrm{H}$, corresponds to the formation of a palladium-deuterium complex. As can be seen in Figure 2, this reduction peak shifts towards more negative potentials with the increase in ${ }^{2} \mathrm{H}$ concentration $(\approx 20 \mathrm{mV}$ shift with every increase). Figure 1 shows the second cycle of the scan because the reduction peak decreases on sequential scans; this indicates a saturation process, which is in agreement with the known behavior of palladium nanoparticles [17]. In the same respect, the oxidation plateau also shifts towards $0 \mathrm{~V}$ (Figure 2A). Another observation is the increase in the capacitance of the electric double layer with the concentration of ${ }^{2} \mathrm{H}$. This effect is explained by the saturation effect of the $\mathrm{Pd}$ nanoparticles, combined with the depletion of ${ }^{2} \mathrm{H}$ in the immediate surroundings of the surface of the electrode. The hydrogen isotope is tightly locked in the matrix of the metal and the desorption rate is slow (Figure 2B).

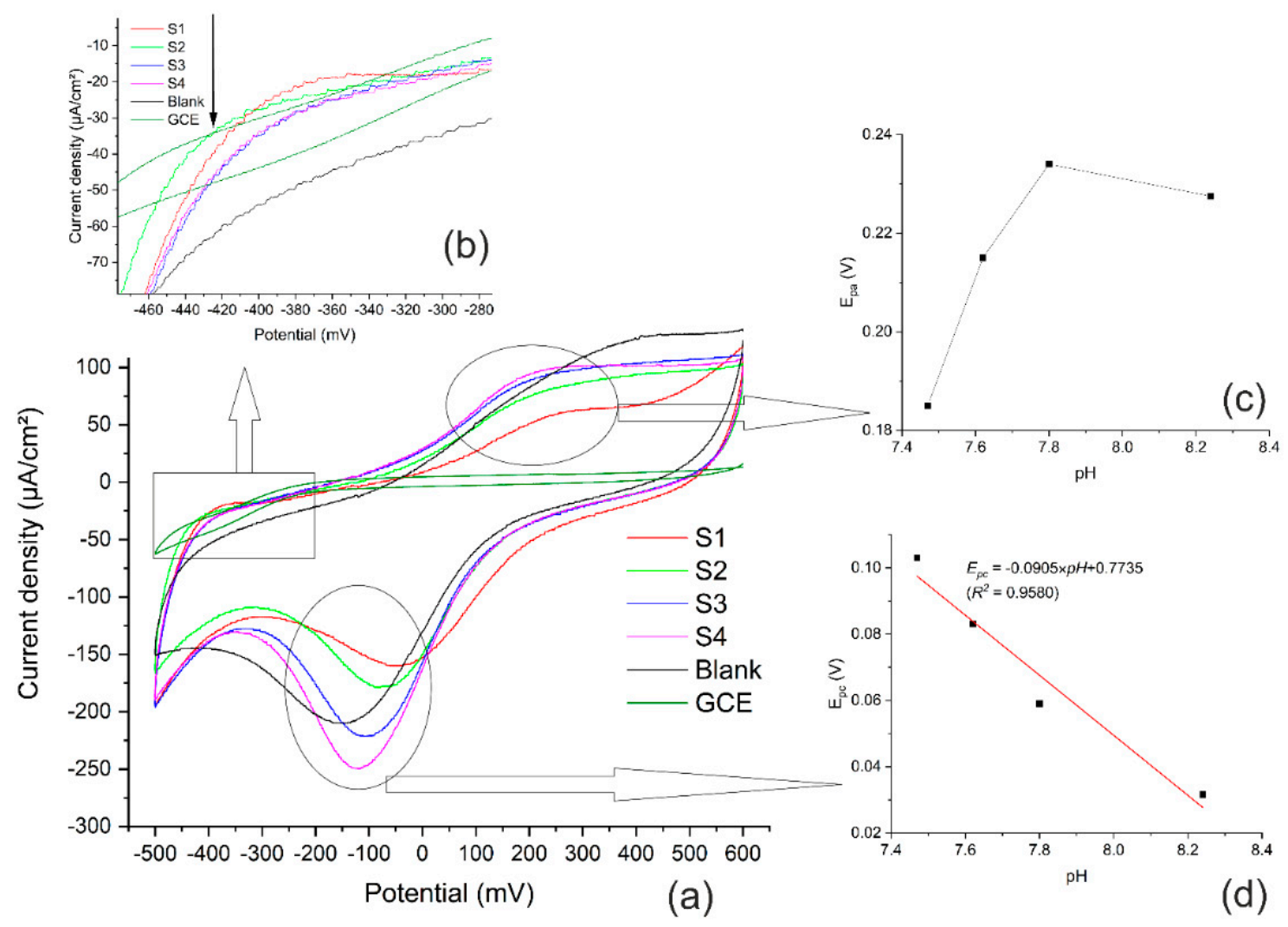

Figure 2. Cyclic voltammetry of the Pd/MWCNT composite in different concentrations of deuterated water (a): in the inset (b) it is shown the increase in the capacitance of the electric double layer; (c) shows the effect of the $\mathrm{pH}$ of the solution on the anodic and cathodic current $(\mathbf{d})$.

Since the concentration of ${ }^{2} \mathrm{H}$ has a direct effect on the $\mathrm{pH}$ of the solution and the modification of the potential, Figure 2c,d show the catalytic performance of the Pd/MWCNT composite. For the anodic wave, for $\mathrm{pH}$ values below 8 , the peak potential shifts toward negative values; for values above 8 , the peak potential increases slightly (moves toward more positive values). This suggests that, at higher concentrations of ${ }^{2} \mathrm{H}, \mathrm{Pd}$ nanoparticles reach their saturation level and the active sites of the composite are blocked.

As a function of $\mathrm{pH}$, the cathodic potential exhibits a linear dependence, with a regression equation:

$$
E_{p c}=-0.0905 \times p H+0.7735
$$


with $R^{2}=0.9580$. In Equation (3) [18]:

$$
\frac{d E_{p c}}{d p H}=-2.303 \frac{m \mathrm{RT}}{n \mathrm{~F}}
$$

$m / n$ represents the ratio between the protons and electrons exchanged in the reaction. In this particular case, the value of $m / n$ is equal to 1.5, implying that three protons and two electrons are employed in the reaction. This suggests that $\mathrm{Pd}$ nanoparticles react with ${ }^{1} \mathrm{H}$ and $1^{2} \mathrm{H}$ every sweep of the electrochemical cycle (note that the abundance of ${ }^{2} \mathrm{H}$ isotopes in nature is $0.02 \%$ ), according to the equilibria:

$$
\mathrm{Pd}+{ }^{1} \mathrm{H}+{ }^{2} \mathrm{H} \rightleftarrows \mathrm{Pd}-{ }^{1} \mathrm{H}-{ }^{2} \mathrm{H}
$$

Figure 3 presents the effect of scan rates on both current peaks and potential for the $\mathrm{Pd} / \mathrm{MWCNT} / \mathrm{GCE}$ composite in $2100 \mathrm{ppm}{ }^{2} \mathrm{H}$ solution. The cyclic voltammetry spectra show an increase for $\mathrm{I}_{\mathrm{pc}}$ (cathodic current) and $\mathrm{E}_{\mathrm{pc}}$ (cathodic potential) with the increases in scan rates. The increase has linear dependence, following the regression equations:

$$
\begin{aligned}
& I_{p c}=6.3423 \times v^{1 / 2}+14.7083, \text { with } R^{2}=0.9832 \\
& E_{p c}=0.1082 \times \log v-0.1206, \text { with } R^{2}=0.9891
\end{aligned}
$$

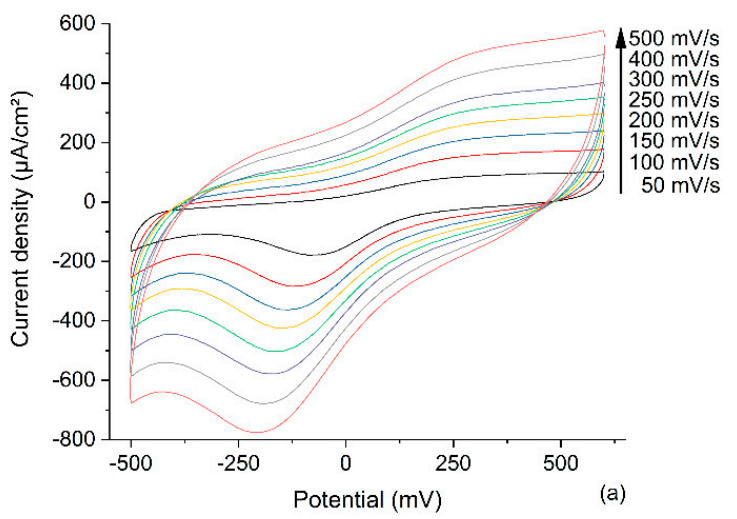

on the current peaks (b) and potential (c).

Equation (5) suggests a diffusion-controlled transfer process, while Equation (6) gives the number of electrons exchanged during the rate determining step $\left(\mathrm{n}_{\alpha}\right)$. From the Tafel slope (Equation (6)) $[9,19,20]$ and considering that the electron transfer coefficient $(\alpha)$ is equal to 0.5 , then $\mathrm{n}_{\alpha}$ is equal to 1 .

$$
E_{p c}=\left[\frac{2.303 R T}{(1-\alpha) n_{\alpha} \mathrm{F}}\right] \log v+\text { constant }
$$


This indicates that one electron, corresponding to the $1 \mathrm{H}$ atom, is transferred in the rate determining step and that the other electron, corresponding to the other hydrogen atom, is transferred during a diffusion-controlled process.

Figure 4 presents the analytical curve for the detection of ${ }^{2} \mathrm{H}$ using the Pd/MWCNT/GCE electrode. The analytical response is given by the linear regression equation:

$$
I_{p c}=0.0042 \times\left[{ }^{2} \mathrm{H}\right]+38.7614, \text { with } R^{2}=0.9237
$$

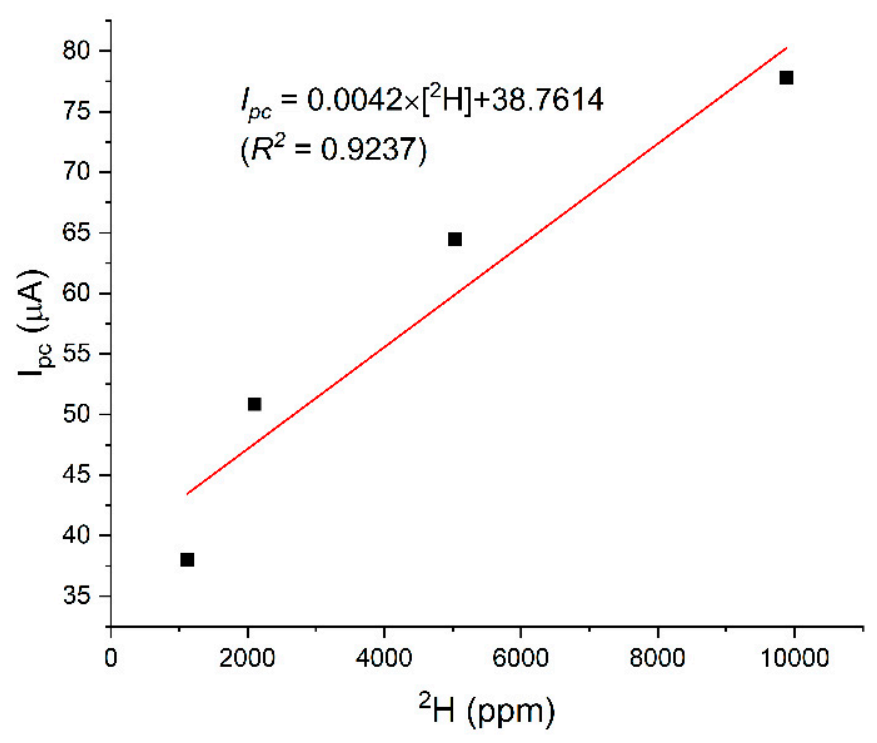

Figure 4. Concentration of ${ }^{2} \mathrm{H}$ water vs. current.

The graph presented in Figure 4 was obtained by the multiplication of the raw current data $\left(\mathrm{I}_{\mathrm{pc}}\right.$ in Table 1$)$ with the area of the modified electrode $\left(0.5024 \mathrm{~cm}^{2}\right)$. The correlation coefficient is low (with a value of 0.9237 ) due to isotopic exchange $\left({ }^{1} \mathrm{H} \rightleftarrows{ }^{2} \mathrm{H}\right.$, the natural abundance of deuterium is $0.02 \%$ ) and different errors that appear in the work flow.

The EIS measurements were used to give an estimation about the interfacial electron transfer kinetics. The diameter of the semicircle in a Nyquist plot (Figure 5) corresponds to a combination of the double layer capacitance $\left(C_{d l}\right)$ and the electron transfer resistance $\left(R_{e t}\right)$, while the straight line is associated with the mass transfer and corresponds to the Warburg resistance $\left(Z_{W}\right)$. Table 2 summarizes the values obtained for the diameter of the semicircles in each solution and the angle for Warburg resistance. For the GCE, there is only the Warburg resistance, which indicates a minimal mass transfer. The highest resistance is observed for the 1120 ppm concentration, suggesting a slow electron transfer, while the lowest resistance is for concentrations of $5030 \mathrm{ppm}$ and $2100 \mathrm{ppm}$, relaying an enhanced electrical conductivity. The results observed from the EIS measurements can be explained by the fact that, when exposed to air, deuterated water reaches equilibrium by isotopic exchange.

Table 2. The variation in the diameter of the semicircle given by the Faradaic charge transfer process with the concentration of ${ }^{2} \mathrm{H}$, resulting from the Nyquist plots.

\begin{tabular}{ccc}
\hline $\begin{array}{c}\text { Sample Concentration } \\
\text { of }{ }^{2} \mathbf{H}(\mathbf{p p m})\end{array}$ & $\mathbf{D}_{\text {semicircle }}(\boldsymbol{\Omega})$ & Angle $\left.\mathbf{(}^{\mathbf{(}}\right)$ \\
\hline GCE & - & 64.4 \\
Blank & 105.3 & 64.8 \\
1120 & 121.3 & 64.85 \\
2100 & 97.7 & 64.7 \\
5030 & 95.0 & 63.4 \\
9880 & 109.3 & 63.09 \\
\hline
\end{tabular}



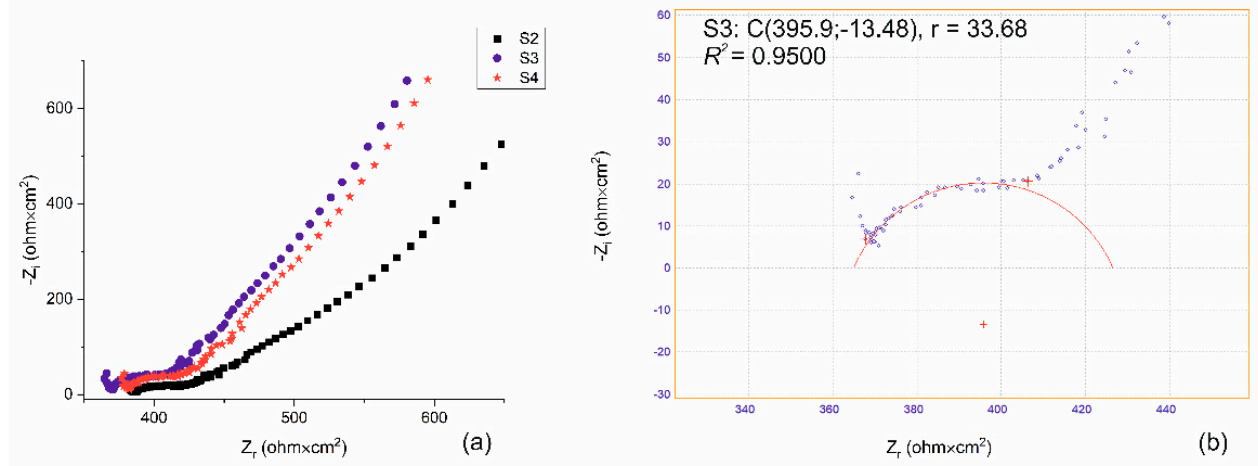

Figure 5. (a) The Nyquist plots for Pd/MWCNT in three concentrations (2100 ppm (S2), 5030 ppm (S3) and $9880 \mathrm{ppm}(\mathrm{S} 4))$. (b) The semicircle fit results for sample S3 (5030 ppm $\left.{ }^{2} \mathrm{H}\right)$ are presented in the inset.

\section{Conclusions}

We presented a study focused on the electrochemical characterization of a nanocomposite based on $\mathrm{Pd} / \mathrm{MWCNTs}$ prepared by a micellization process. The synthesis route uses mild reaction conditions and simple precursors $\left(\mathrm{PdCl}_{2}\right.$, hydrazine, room temperature conditions, easy-to-obtain solvents) to obtain Pd particles with sizes below $10 \mathrm{~nm}$. The electrochemical analysis was performed on four samples with different concentrations of deuterium isotopes. As a blank sample, a commercially available type of water with a low concentration of ${ }^{2} \mathrm{H}$ was used. The electrochemistry indicates that one electron, corresponding to one hydrogen atom, is transferred in the rate determining step and that the other electron, corresponding to the other hydrogen atom, is transferred during a diffusion-controlled process. The process is quasi-reversible with the reduction curve more pronounced then the oxidation curve, which indicates a low tendency to desorption or the hydrogen atoms. The analytical curve for the detection of ${ }^{2} \mathrm{H}$ using the Pd/MWCNT/GCE electrode is given by a linear regression equation, which has a low correlation factor due to isotopic exchange and cumulative errors during the preparation and testing of the samples.

Judging from this regression equation, it looks like electrochemical detection depends on the quality and quantity of the samples that are investigated, and this detection method can be improved by increasing the number of samples and the distribution of concentrations in order to obtain satisfactory means for the determination of hydrogen isotopes in aqueous media.

Author Contributions: Conceptualization, S.-M.I., E.I.I. and I.S.; methodology, A.-M.I. and C.E.A.G.; formal analysis, S.-M.I. and A.-M.I.; investigation, A.-M.I., A.S. and N.C.Z.; writing—original draft preparation, S.-M.I. and A.-M.I.; writing—review and editing, I.S. and C.E.A.G.; supervision, I.S. and C.E.A.G.; project administration, S.-M.I. and A.-M.I.; funding acquisition, S.-M.I., A.-M.I. and C.E.A.G. All authors have read and agreed to the published version of the manuscript.

Funding: This work was supported by a grant of the Romanian Ministry of Education and Research, CNCS-UEFISCDI, project number PN-III-P1-1.1-PD-2019-1134, PN-III-P2-2.1-PED-2019-2551 and CORE Programme, Ctr. 18/N/2019.

Institutional Review Board Statement: Not Applicable.

Informed Consent Statement: Not Applicable.

Data Availability Statement: The data presented in this study are available on request from the corresponding author.

Acknowledgments: The authors wish to express their gratitude to Diana Costinel for preparing the ${ }^{2} \mathrm{H}$ water samples.

Conflicts of Interest: The authors declare no conflict of interest. 


\section{References}

1. Lozada-Hidalgo, M.; Zhang, S.; Hu, S.; Esfandiar, A.; Grigorieva, I.V.; Geim, A.K. Scalable and efficient separation of hydrogen isotopes using graphene-based electrochemical pumping. Nat. Commun. 2017, 8, 15215. [CrossRef] [PubMed]

2. Miles, M.H.; Johnson, K.B.; Imam, M.A. Electrochemical loading of hydrogen and deuterium into palladium and palladium-boron alloys. In Sixth International Conference on Cold Fusion, Progress in New Hydrogen Energy; New Energy and Industrial Technology Development Organization: Lake Toya, Japan; Tokyo Institute of Technology: Tokyo, Japan, 1996.

3. Denuault, G.; Milhano, C.; Pletcher, D. Mesoporous Palladium-The surface electrochemistry of palladium in aqueous sodium hydroxide and the cathodic reduction of nitrite. Phys. Chem. Chem. Phys. 2005, 7, 3545-3551. [CrossRef] [PubMed]

4. Petrăşescu, L.; Ciupină, V.; Tutun, Ş.G.; Vlădoiu, R.; Prodan, G.; Poroşnicu, C.; Vasile, E.; Prioteasa, I.; Manu, R. Carbon—Platinum nanostructured catalysts for hydrogen fuel cells. J. Optoelectron. Adv. M. 2015, 17, 1464-1470.

5. Grigorescu, C.E.A.; Zoita, C.N.; Sobetkii, A.; Iordache, A.-M.; Iordache, S.-M.; Stefan, C.R.; Rusu, M.I.; Tortet, L.; Tonetto, A. Multinary metal alloys of the Heusler, half-Heusler, dilute magnetic semiconductors, and high entropy families: How would spin make a choice? J. Optoelectron. Adv. M. 2020, 22, 647-652.

6. Grdeń, M.; Kotowski, J.; Czerwinski, A. The study of electrochemical palladium behavior using the quartz crystal microbalance. J. Solid State Electrochem. 2000, 4, 273-278. [CrossRef]

7. Grdeń, M.; Łukaszewski, M.; Jerkiewicz, G.; Czerwiński, A. Electrochemical behaviour of palladium electrode: Oxidation, electrodissolution and ionic adsorption. Electrochim. Acta 2008, 53, 7583-7598. [CrossRef]

8. Pujol, L.; Evrard, D.; Serrano, K.G.; Freyssinier, M.; Ruffien-Cizsak, A.; Gros, P. Electrochemical sensors and devices for heavy metals assay in water: The French groups' contribution. Front. Chem. 2014, 2, 19. [CrossRef] [PubMed]

9. Jaksic, M.; Johansen, B.; Tunold, R. Electrochemical behaviour of palladium in acidic and alkaline solutions of heavy and regular water. Int. J. Hydrog. Energy 1993, 18, 111-124. [CrossRef]

10. Iordache, S.M.; Ionete, E.I.; Iordache, A.M.; Tanasa, E.; Stamatin, I.; Grigorescu, C.E.A. Pd-decorated CNT as sensitive material for applications in hydrogen isotopes sensing - Application as gas sensor. Int. J. Hydrog. Energy 2021, 46, 11015-11024. [CrossRef]

11. Iordache, A.-M.; Rizea, C.; Giuglea, C.; Zoita, C.N.; Stamatin, I.; Iordache, S.M.; Stefan, C.R.; Rusu, M.I.; Tortet, L.; Tonetto, A.; et al. Grigorescu, Preparation and Study of Core Shell Fe3O4/Au Nanoparticles for Traceability of Blood Vessels and Biosensing by Surface Enhanced Raman Spectroscopy. In Proceedings of the 2020 22nd International Conference on Transparent Optical Networks (ICTON), Bari, Italy, 19-23 July 2020; 2020; pp. 1-4. [CrossRef]

12. Kim, C.; Hsieh, Y.-L. Wetting and absorbency of nonionic surfactant solutions on cotton fabrics. Colloids Surf. A Physicochem. Eng. Asp. 2001, 187-188, 385-397. [CrossRef]

13. National Center for Biotechnology Information. PubChem Compound Summary. Available online: https://pubchem.ncbi.nlm. nih.gov/ (accessed on 1 July 2021).

14. Japan Nuclear Cycle Development Institute. Thermodynamic Data for the Speciation and Solubility of $\mathrm{Pd}, \mathrm{Pb}, \mathrm{Sn}, \mathrm{Sb}, \mathrm{Nb}$ and Bi in Aqueous Solution. 1999. Available online: https://inis.iaea.org/search/search.aspx?orig_q=RN:31009694 (accessed on 1 July 2021).

15. Girault, H.H. Analytical and Physical Electrochemistry; EPFL: Lausanne, Switzerland, 2004.

16. Schuldiner, S.; Hoare, J.P. Mechanisms of Hydrogen Producing Reactions on Palladium, V. The Deuterium-Palladium System. J. Electrochem. Soc. 1958, 105, 278. [CrossRef]

17. Cincotto, F.H.; Golinelli, D.L.; Machado, S.A.; Moraes, F.C. Electrochemical sensor based on reduced graphene oxide modified with palladium nanoparticles for determination of desipramine in urine samples. Sens. Actuators B Chem. 2017, 239, 488-493. [CrossRef]

18. Zhang, Y.; Huang, B.; Ye, J.; Ye, J. A sensitive and selective amperometric hydrazine sensor based on palladium nanoparticles loaded on cobalt-wrapped nitrogen-doped carbon nanotubes. J. Electroanal. Chem. 2017, 801, 215-223. [CrossRef]

19. Karuppiah, C.; Velmurugan, M.; Chen, S.-M.; Devasenathipathy, R.; Karthik, R.; Wang, S.-F. Electrochemical Activation of Graphite Nanosheets Decorated with Palladium Nanoparticles for High Performance Amperometric Hydrazine Sensor. Electroanalysis 2015, 28, 808-816. [CrossRef]

20. Devasenathipathy, R.; Mani, V.; Chen, S.-M. Highly selective amperometric sensor for the trace level detection of hydrazine at bismuth nanoparticles decorated graphene nanosheets modified electrode. Talanta 2014, 124, 43-51. [CrossRef] 